\title{
Stability and binding affinity of DNA/chitosan complexes by polyanion competition
}

\section{Ma, Pei Lian}

2017-11-15

Ma , P L , Lavertu , M , Winnik , F M \& Buschmann , M D 2017 , ' Stability and binding affinity of DNA/chitosan complexes by polyanion competition ' , Carbohydrate Polymers, vol. 176 , pp. 167-176 . https://doi.org/10.1016/j.carbpol.2017.08.002

http://hdl.handle.net/10138/308022

https://doi.org/10.1016/j.carbpol.2017.08.002

cc_by_nc_nd

acceptedVersion

Downloaded from Helda, University of Helsinki institutional repository.

This is an electronic reprint of the original article.

This reprint may differ from the original in pagination and typographic detail.

Please cite the original version. 


\title{
Stability and Binding Affinity of DNA/Chitosan
}

\section{Complexes by Polyanion Competition}

\author{
Pei Lian Ma, ${ }^{\dagger}$ Marc Lavertu, Françoise M. Winnik, ${ }^{*+}$ and Michael D. Buschmann ${ }^{*}+\dagger$
}

Department of Chemical Engineering and Institute of Biomedical Engineering, Polytechnique Montréal, PO 6079 Succ. Centre-Ville, Montreal, Quebec, H3C 3A7, Canada, and Department of Chemistry and Faculty of Pharmacy, Université de Montréal, PO 6128 Succ. Centre-Ville, Montreal, Quebec, H3C 3J7, Canada.

pei-lian.ma@polymtl.ca,michael.buschmann@polymtl.ca, francoise.winnik@umontreal.ca

*To whom correspondence should be addressed: Michael D. Buschmann, tel 1-514-340-4711 ext. 4931, fax 1-514-340-2980, email michael.buschmann@polymtl.ca. Françoise M. Winnik, tel: 1-514340-5179, fax: 1-514-340-5292, email: francoise.winnik@umontreal.ca.

†Polytechnique Montréal

†Université de Montréal 


\begin{abstract}
The stability of DNA/chitosan complexes upon exposure to hyaluronic acid, chondroitin sulfate, and heparin, was assessed by fluorescence spectroscopy to quantify DNA release. Only the highly charged heparin was found to release DNA from the complexes. Complex stability upon exposure to heparin increased with the degree of deacetylation and molecular weight of chitosan and with the ratio of chitosan amino groups to DNA phosphate groups (N/P ratio) in the complexes. Isothermal titration microcalorimetry revealed that among polyanions tested, only heparin has a binding affinity to chitosan approaching that of DNA and can therefore release DNA from the complexes. These results also indicate that anionic components with sufficiently high charge density can induce extracellular or intracellular release of DNA, the former negatively affecting delivery efficiency while the latter is required for gene transfer to occur. Our findings also suggest that increased N:P ratio of the complexes can play an important role in preventing premature dissociation of DNA/polycation complexes upon interaction with anionic components in extracellular milieu.
\end{abstract}




\section{Introduction}

Significant progress has been made in understanding the formation of polyelectrolyte complexes of cationic polymers and nucleic acids (NA), their internalization into the cells and subsequent trafficking. It is commonly accepted that NA/polycation complexes are taken up by cells via endocytosis but further stages of their endosomal release into the cytoplasm, their transport to the nucleus, and the release of the genes for their expression are less well understood. One mechanism of endosomal release of the complexes into the cytoplasm is based on the proton sponge hypothesis $[1,2]$. Published studies have demonstrated that several cationic polymers, such as the widely used polyethyleneimine (PEI),[3-5] dendrimers,[6] and chitosan,[7] have the ability to buffer endosomal acidification causing an accumulation of protons and an influx of chloride anions, resulting in an increase of osmotic pressure with entry of water and thereby the disruption of the endosome. It is worth mentioning that membrane destabilization by free polycation has been proposed as another mechanism that could also contribute to endosomal release of the highly charged PEI [8-11].

For efficient in vitro and in vivo transfection, an excess of polycation is often used to formulate with DNA, such that the molar ratio of polycation protonable amino groups to DNA phosphate groups (N/P ratio) is usually higher than 3. Under such conditions, data obtained from recent studies characterizing PEI or chitosan-based formulations using different analytical techniques revealed that more than $50 \%$ of the polycation remains free in solution, unbound to DNA [12-17]. The presence of free polycation in DNA/chitosan complexes dispersions has been shown to be required to mediate efficient transfection as it facilitates lysosomal escape [18]. This finding is supported by theoretical calculations that predicted that DNA/polycation complexes alone cannot trigger their endosomal escape through the proton sponge mechanism without a sufficiently high content of free polycation inside the endosome [3].

Once outside the endosome, DNA has to dissociate from the polycation and be transported into the nucleus for transcription. The intracellular DNA unpackaging from its vector has been demonstrated to be a limiting factor for efficient gene expression in non-viral systems [19]. In line with this finding, the acetylation of PEI was seen to decrease DNA-polycation binding, leading to more facile 
unpackaging of the complexes [20]. Gene expression levels were decreased or inhibited when DNA was either tightly or loosely bound to the polycation, such as PEI [20-23] and chitosan [24-27]. Tightly bound and highly stable complexes will be readily endocytosed but possibly not disassembled to access the transcription machinery. On the other hand, DNA weakly bound to the polycation forms complexes that will dissociate prematurely in the medium and not even be endocytosed into cells. Effective gene delivery has been related to an appropriate balance between the DNA-polycation binding strength and the ability to dissociate intracellularly for gene expression $[25,26,28-30]$.

Gene delivery can be affected by non-specific interactions of DNA/polycation complexes with anionic biological components, including serum proteins, cytoplasmic RNA and glycoaminoglycans. Being present in the cytoplasm at high concentrations and structurally similar to DNA, RNA was found to induce DNA dissociation from polyamine gene vectors preferentially in the cytoplasm prior to enter the nucleus for gene expression [30]. Glycosaminoglycans, such as hyaluronic acid (HA), chondroitin sulfate (CS), and heparin (Hp), are linear negatively charged polymers of repeating disaccharides that are found abundantly in the extracellular matrix, intracellulary, and on the plasma membrane associated with cell surface receptors and adhesion molecules [31]. They can destabilize the DNA/polycation complexes by competing with DNA for binding to the polycation, resulting in the dissociation of the complexes and premature release of DNA extracellularly [32]. Labeled heparin sulfate was found previously to decrease cellular uptake and gene expression of DNA/PEI complexes, and was mostly bound to the polycation inside the cells as detected by confocal microscopy [33]. However, the binding of HA [22, 34-37] and CS [38] to positively charged DNA/polycation complexes was recently found to mediate gene delivery without disrupting the complexes. Ternary complexes resulted from the coating approach aim at protecting the complexes from non-specific interactions with serum proteins and loosening the tight binding between DNA and the polycation to facilitate intracellular unpackaging. These polysaccharides were also recently found to enhance the preservation of DNA/PEI [39] and DNA/chitosan [40] complexes after freezedrying without adding lyoprotectants. Nevertheless, the stability of DNA/polycation complexes in 
the presence of serum proteins and competing polyanions, such as HA and heparin, has been commonly assessed by gel electrophoresis to detect released DNA [26, 41, 42]. In the majority of cases, only the highly charged heparin was able to dissociate the complexes. Fluorescence spectrophotometry together with ethidium bromide as a probe for DNA was also used to investigate the formation of DNA/polycation complexes [43-46] and their dissociation by competing polyanions $[32,47]$. Yet, the majority of studies on the stability of polymeric DNA complexes in the presence of biological polyanions were descriptive and provided little if any quantitative information about the release of DNA as well as the polycation binding affinity with DNA and with the competing polyanions.

We report here the stability behavior of DNA/chitosan complexes upon exposure to biological polyanions using fluorescence spectrophotometry. Chitosan was selected as the polycation because it is the most frequently used natural polymer for the delivery of nucleic acid [48]. The biological polyanions used to compete with DNA for binding to chitosan include HA, CS, and Hp, which differ in sulfate content and charge density. Isothermal titration microcalorimetry (ITC) was used to study the interaction of chitosan with DNA and with each competing polyanion. The binding constants of the binary systems determined from ITC measurements were then compared and correlated with the ability of the competing polyanions to disrupt DNA/chitosan complexes. The unbound or released DNA was quantified using fluorescence spectrophotometry and Picogreen which is a cyanine dye that preferentially binds to double stranded DNA. The effect of chitosan structural parameters on the stability of these complexes was assessed, including the chitosan molecular weight and the degree of deacetylation (DDA) which directly controls charge density. These parameters are known to influence the binding affinity of chitosan with DNA [28] and the transfection efficiency of the complexes. [24-26, 49, 50]. We also examined the effect of increasing the free chitosan content on the stability the complexes by varying the chitosan amino groups to DNA phosphate groups (N/P) ratio used in the formulations. 


\section{Experimental Section}

Materials. The $6.4 \mathrm{~kb}$ plasmid EGFPLuc (Clontech Laboratories) was amplified in DH5 $\alpha$ bacteria and purified using the Qiagen Plasmid Mega Kit. A stock solution of this plasmid $(0.33 \mathrm{mg} / \mathrm{mL})$ was prepared in deionized water and stored at $-20^{\circ} \mathrm{C}$ before use. Ultrapure heterogeneously deacetylated chitosans (Ultrasan ${ }^{\mathrm{TM}}$ ) with a DDA of $72 \%, 80 \%$, and 98\% were from Marinard (Rivière-au-Renard, Qc, Canada) and were depolymerized according to Lavertu et al [25] using nitrous acid to achieve specific number-average molecular weight $\left(M_{\mathrm{n}}\right)$ ranging from 11 to $153 \mathrm{kDa}$. Table 1 summarizes the resulting $M_{\mathrm{n}}$ and polydispersity index of chitosans measured by size-exclusion chromatography with multi-angle light scattering (SEC-MALS) [51] as well as the DDA determined by ${ }^{1} \mathrm{H}$ NMR [52]. Chitosan stock solutions of $5 \mathrm{mg} / \mathrm{mL}$ were prepared by dissolving the samples overnight in deionized water and hydrochloric acid (from $1 \mathrm{M} \mathrm{HCl}$ solution), such as to reach an $\mathrm{HCl} /$ glucosamine ratio of 1 .

Chondroitin-6-sulfate sodium salt (CS) from shark cartilage (Sigma-Aldrich, C4384) and heparin sodium salt (Hp) from porcine intestinal mucosa (Sigma-Aldrich, H3149) were used as the competing polyanions. A high molecular weight hyaluronic acid sodium salt (HA1, >1 MDa) from Sigma-Aldrich (H5388) and a hyaluronic acid sodium salt with a $M_{\mathrm{n}}$ of $21 \mathrm{kDa}$ (HA2) from Lifecore USA were also used. The $M_{\mathrm{n}}$ and polydispersity index of these polyanions determined by GPC [53] are shown in Table 1. The structure of HA, CS, and Hp disaccharides are illustrated in Figure 1. Stock solutions of the polyanion $(1 \mathrm{mg} / \mathrm{mL})$ were prepared in deionized water. Picogreen was provided (Invitrogen) as a $320 \mathrm{mM}$ concentrated stock solution in DMSO. Orange II was from Sigma-Aldrich (195235).

Preparation of DNA/Chitosan Complexes. Prior to mixing, chitosan solutions were diluted with deionized water to reach the desired molar N/P ratio (chitosan protonable amine to DNA phosphate ratio) when $50 \mu \mathrm{L}$ of chitosan would be mixed with $50 \mu \mathrm{L}$ of DNA solution, the latter always at a concentration of $0.33 \mathrm{mg} / \mathrm{ml}$ in deionized water. The mixing was done quickly by up and down 
pipetting of the dispersions. Samples were allowed to incubate at room temperature 30 min before analysis.

Table 1. Molecular Characteristics of Chitosans and Polyanions.

\begin{tabular}{lccc}
\hline Polyelectrolyte & DDA & $M_{\mathrm{n}}(\mathrm{kDa})^{a}$ & $M_{\mathrm{w}} / M_{\mathrm{n}}{ }^{a}$ \\
\hline Chitosan & $72 \%$ & 86 & 3.5 \\
& $80 \%$ & 11 & 1.4 \\
& $80 \%$ & 76 & 1.6 \\
& $80 \%$ & 153 & 1.6 \\
$\mathrm{Hp}$ & $98 \%$ & 79 & 1.6 \\
$\mathrm{CS}$ & & 32 & 2.8 \\
$\mathrm{HA}^{a}{ }^{a}$ & & 25 & 1.4 \\
$\mathrm{HA}^{2}$ & & $>1000^{b}$ & --- \\
\end{tabular}

${ }^{a}$ By GPC analysis except where indicated. ${ }^{b}$ Provided by the supplier.

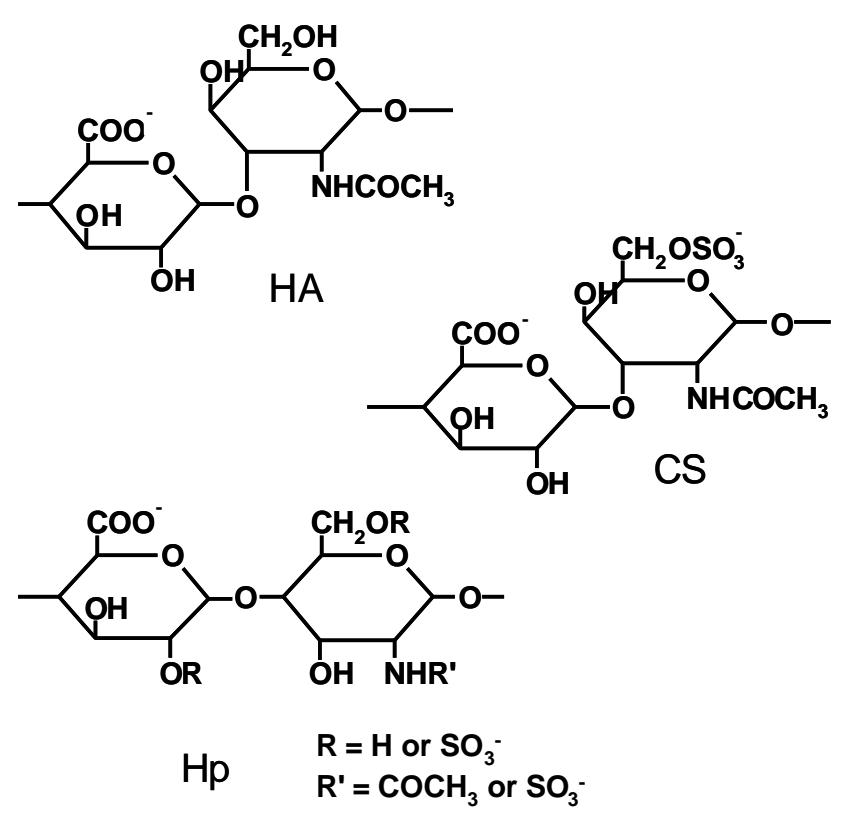

Figure 1. Disaccharide repeating units of Hyaluronic Acid (HA), Chondroitin-6-Sulfate (CS), and Heparin (Hp).

Polyanion Competition Binding Assay. Dispersions of DNA/chitosan complexes (50 $\mu \mathrm{L})$ were diluted with $25 \mathrm{mM}$ MES buffer $(1.2 \mathrm{~mL})$ at $\mathrm{pH} 6.5$ with a total ionic strength of $150 \mathrm{mM}$ (adjusted by addition of $\mathrm{NaCl}$ ). These samples were allowed to equilibrate for $30 \mathrm{~min}$ in the $\mathrm{pH}$-adjusted MES 
buffer before analysis. We used 96-well black plates (Fisher, no.CS003915) for this assay and added $30 \mu \mathrm{L}$ of sample per well. We then added $70 \mu \mathrm{L}$ of competing polyanion solution at a concentration of 5 or $24 \mu \mathrm{g} / \mathrm{mL}$ prepared by diluting the stock solution $(1 \mathrm{mg} / \mathrm{mL})$ in $25 \mathrm{mM}$ MES buffer adjusted to $\mathrm{pH}$ 6.5. For the controls without the competing polyanion, $70 \mu \mathrm{L}$ of the MES buffer was added to the wells. The mixing was done on a rocking agitation table for $60 \mathrm{~min}$ at $150 \mathrm{rpm}$. Picogreen, a cyanine that preferentially binds to double stranded DNA through intercalation between the base pairs $[54,55]$, was then used to quantify the free or released DNA before and after exposure to the competing polyanions. It is worth mentioning that Picogreen has an absorption coefficient about 12fold greater compared to ethidium bromide $[56,57]$ and has previously shown to be more sensitive in the quantification of released DNA from gene delivery systems [58]. A 200-fold dilution of the Picogreen stock solution was prepared in MES buffer and a volume of $100 \mu \mathrm{L}$ was added to each well. The mixing was done quickly by up and down pipetting of the mixtures. The final volume and the DNA concentration in each well were $200 \mu \mathrm{L}$ and $0.99 \mu \mathrm{g} / \mathrm{mL}$, respectively. After 2 min of incubation, the fluorescence intensity of the samples was measured using a microplate spectrofluorometer (Spectramax Gemini XS, Molecular Devices, Sunnyvale, CA) at excitation and emission wavelengths of 485 and $535 \mathrm{~nm}$, respectively. The blank containing $100 \mu \mathrm{L}$ of MES buffer and $100 \mu \mathrm{L}$ of diluted Picogreen solution was subtracted from the measurements. The reported fluorescence intensity for each N/P ratio is relative to the control containing $0.99 \mu \mathrm{g} / \mathrm{mL}$ of DNA without chitosan $(\mathrm{N} / \mathrm{P}=0)$ and represents the mean value ( \pm S.D.) of three independent measurements.

Isothermal Titration Calorimetry. Binding studies were performed using a VP-ITC microcalorimeter from MicroCal (Northampton, MA) with a cell volume of $1.428 \mathrm{~mL}$ at $25^{\circ} \mathrm{C}$. Samples were degassed in a ThermoVac system (MicroCal) prior to use. The reference cell was filled with $25 \mathrm{mM}$ MES buffer ( $\mathrm{pH} 6.5$, total ionic strength of $150 \mathrm{mM}$ adjusted by addition of $\mathrm{NaCl})$ solution only. The sample cell was filled with the polyanion, either with the DNA solution (40 $\mu \mathrm{g} / \mathrm{mL})$, Hp solution (33 $\mu \mathrm{g} / \mathrm{mL})$, CS solution $(60 \mu \mathrm{g} / \mathrm{mL})$, or HA2 solution $(78 \mu \mathrm{g} / \mathrm{mL})$, all prepared 
using the MES buffer. These concentrations were optimized to obtain sigmoidal shape isotherms with a high signal-to-noise ratio but avoiding step functions that are not reliable for determining the binding constant. The shortest chitosan was chosen as the ligand in this study $\left(80 \% \mathrm{DDA}, \mathrm{M}_{n}=11\right.$ $\mathrm{kDa}$ ), saturating progressively the free binding sites of the polyanion upon titration, the latter being considered as the macromolecule or host. The chitosan stock solution of $5 \mathrm{mg} / \mathrm{mL}$ was diluted using the MES buffer to a concentration of $154 \mu \mathrm{g} / \mathrm{mL}$ in the titrations of chitosan into DNA or Hp, and to a concentration of $462 \mu \mathrm{g} / \mathrm{mL}$ in the titrations of chitosan into CS or HA2. The solution of chitosan was introduced into the thermostated cell by means of a syringe which also stirred at $250 \mathrm{rpm}$. Each titration consisted of an initial $2 \mu \mathrm{L}$ injection (neglected in the analysis) followed by 28 subsequent $10 \mu \mathrm{L}$ injections each of which were $20 \mathrm{~s}$ in duration and were programmed to occur at $400 \mathrm{~s}$ intervals. The heats of dilution from titrations of chitosan solution into buffer only (without DNA or competing polyanion) were subtracted from the heats obtained from titrations of chitosan solution into the DNA or competing polyanion solution to obtain net binding heats. All experiments were carried out in duplicate.

Analysis of Binding Isotherms. Raw ITC data of chitosan binding to a polyanion (DNA, Hp, CS, or HA) polyanion was processed with the Origin software provided by the manufacturer (MicroCal, Northampton, MA). The isotherms were fit as previously described [28] using the Single Set of Identical Sites (SSIS) model by a nonlinear least-squares analysis $[59,60]$. The equilibrium binding constant, $K$, between a free molecule of chitosan and a free binding site on the polyanion is represented by Equation 1, assuming independent binding sites.

$$
\begin{gathered}
\text { Free binding site on polyanion }+ \text { Free chitosan } \stackrel{K}{\leftrightarrows} \text { Bound chitosan } \\
\qquad K=\frac{[\text { Bound chitosan }]}{[\text { Free binding sites } \llbracket[\text { Free chitosan] }}
\end{gathered}
$$

From the heat changes $(\Delta \mathrm{Q})$ detected by the instrument, we determined the binding affinity, $K$, the enthalpy of binding, $\Delta H$, and the number of binding sites for chitosan, $n$. These parameters are reported as the mean of two measurements with error bars representing the minimum and maximum. 
Quantification of Free Chitosan by Ultracentrifugation and Orange II Dye. Dispersions of DNA/chitosan complexes $(100 \mu \mathrm{L})$ prepared using a chitosan with intermediate DDA and molecular weight of $80 \%$ and $76 \mathrm{kDa}$, respectively, were diluted with $400 \mu \mathrm{L}$ of either deionized water or 25 $\mathrm{mM}$ MES buffer ( $\mathrm{pH} 6.5$, total ionic strength of $150 \mathrm{mM}$ adjusted by addition of $\mathrm{NaCl}$ ). These samples were allowed to rest for $30 \mathrm{~min}$ before subjecting them to ultracentrifugation at $65000 \mathrm{rpm}$ for 30 min (Beckman, Optima MAX-E, TLA-110 fixed rotor). The supernatant of each sample was then recovered to determine the concentration of free chitosan by the Orange II dye depletion method [61]. A volume of $100 \mu \mathrm{L}$ of supernatant was collected and further diluted 6 to 15 fold with $50 \mathrm{mM}$ acetic acid/sodium acetate buffer at $\mathrm{pH} 4.0$, such that the concentration of chitosan amine groups to be assayed would be always lower than that of Orange II at mixing. The diluted supernatant was then mixed with 0.1 volume of $1 \mathrm{mM}$ Orange II solution (in the acetic acid/sodium acetate buffer) by vortexing. After 15 min of incubation, the suspension of chitosan/Orange II was centrifuged (20 000g for $30 \mathrm{~min})$ to precipitate the complexes and recover the supernatant containing the unbound dye. The absorbance of the supernatant was then measured at $484 \mathrm{~nm}$ using a UV/vis spectrophotometer (Beckman DU-600). The free chitosan content in DNA/chitosan dispersions was calculated from calibration curves obtained with solutions of chitosan. The reported values are the average ( \pm standard deviation) of at least three samples.

Polyacrylamide Gel Electrophoresis. Dispersions of DNA/chitosan complexes were diluted 5fold with $25 \mathrm{mM}$ MES buffer at $\mathrm{pH} 6.5$ and left at rest for $30 \mathrm{~min} .25 \mu \mathrm{L}$ of each of these samples was then mixed with $5 \mu \mathrm{L}$ of $40 \%$ sucrose solution. The mixing was briefly done by pipetting. A sample volume of $20 \mu \mathrm{L}(0.66 \mu \mathrm{g}$ of DNA equivalence) was then loaded into a $6 \%$ polyacrylamide gel (20 mM MES, $8 \mathrm{mM}$ sodium acetate, $\mathrm{pH}$ 6.5). Electrophoresis was carried out at $90 \mathrm{~V}$ for 60 min. Chitosan was then stained by immersing the gel in a Coomassie blue staining solution (10:45:45 glacial acetic acid/methanol/deionized water and $0.25 \% \mathrm{w} / \mathrm{v}$ Coomassie brilliant blue R250 (Biorad, M1226)) for $45 \mathrm{~min}$ in a shaker followed by washing with a destaining solution 
(10:30:60 glacial acetic acid/methanol/deionized water) for 4 hours in a shaker. Images of the gel were taken using a ChemImager 5500 system (Alpha Innotech).

Zeta Potential Measurements. Dispersions of DNA/chitosan complexes (100 $\mu \mathrm{L})$ were diluted with $900 \mu \mathrm{L}$ of $25 \mathrm{mM}$ MES buffer (pH 6.5, total ionic strength of $150 \mathrm{mM}$ adjusted by addition of $\mathrm{NaCl}$ ) prior to analysis with a Malvern Zetasizer Nano ZS (Worcestershire, UK). The zeta potential of the complexes was calculated from the electrophoretic mobility values using the Smoluchowski equation [62].

\section{Results and Discussion}

Effect of Charge Density of the Competing Polyanions on the Stability of the Complexes. The biological polyanions selected to compete with DNA for binding to chitosan include hyaluronic acid (HA), chondroitin sulfate (CS), and heparin (Hp). The disaccharide units of these glycoaminoglycans contain carboxyl and sulfate groups, which are fully ionized and negatively charged in a solution $\mathrm{pH}$ of 6.5 used in this study (pKa of carboxyl groups: $2.79-3.13,[63,64] \mathrm{pKa}$ of sulfate groups: 0.5-1.5[65]). Among these polysaccharides, HA has the lowest negative charge density bearing only one carboxyl group on the glucuronic acid residue of each repeating disaccharide unit while CS has one additional sulfate group per disaccharide unit (Figure 1). Hp has the highest negative charge density because it can have multiple sulfate groups per disaccharide unit in addition to a carboxyl group. The content of carboxyl and sulfate groups of Hp was determined by carrying out conductimetric titrations of the acid form of heparin with a solution of $\mathrm{NaOH}$ (See Supporting Information, Figure S-1) [65]. We found a sulfate to carboxyl ratio of 2, indicating an average of two sulfate and one carboxyl groups on each repeating disaccharide unit of Hp. In terms of charge spacing, each disaccharide unit of HA, CS, and Hp has 1, 2, and 3 charges spaced along the approximately $1 \mathrm{~nm}$ disaccharide length.

The ability of these competing polyanions to destabilize and dissociate the DNA/chitosan complexes was assessed by detecting and quantifying free or released DNA using Picogreen. Taking 
into account that a molecule of Picogreen can occupy nearly 5 DNA base pairs, i.e. $1.7 \mathrm{~nm}$ of length,[54] we assumed that detection is only possible for completely free DNA and partially bound DNA exposing free segments with sufficient length to allow Picogreen intercalation. We first prepared dispersions of DNA/chitosan $(80 \% \mathrm{DDA}, 76 \mathrm{kDa})$ complexes at different $\mathrm{N} / \mathrm{P}$ ratios and then mixed each of them with a solution of Picogreen for detection of unbound DNA prior to exposure to competing polyanions. These samples without addition of any competing polyanion correspond to the controls of Figure 2, showing the fluorescence intensities of Picogreen bound to free DNA as a function of the N/P ratio in the dispersions. The reported values are relative to the fluorescence intensity measured upon addition of Picogreen to a solution of DNA at the same concentration as each dispersion but without chitosan $(\mathrm{N} / \mathrm{P}=0)$. The decrease of the fluorescence intensity observed with increasing N/P ratio indicates increasing amounts of DNA complexed with chitosan, in agreement with the zeta potential measurements of the complexes showing gradual neutralisation of the DNA phosphate groups by chitosan (Figure 3). The relative fluorescence intensity of the dye reached an almost constant value of 5\% in the dispersions with N/P ratios above 1.5 (Figure 2), where DNA was fully complexed with chitosan as confirmed by the positive zeta potentials (Figure 3). This residual fluorescence intensity of bound Picogreen, although negligible, may result from some limited access of Picogreen to DNA inside the complexes.

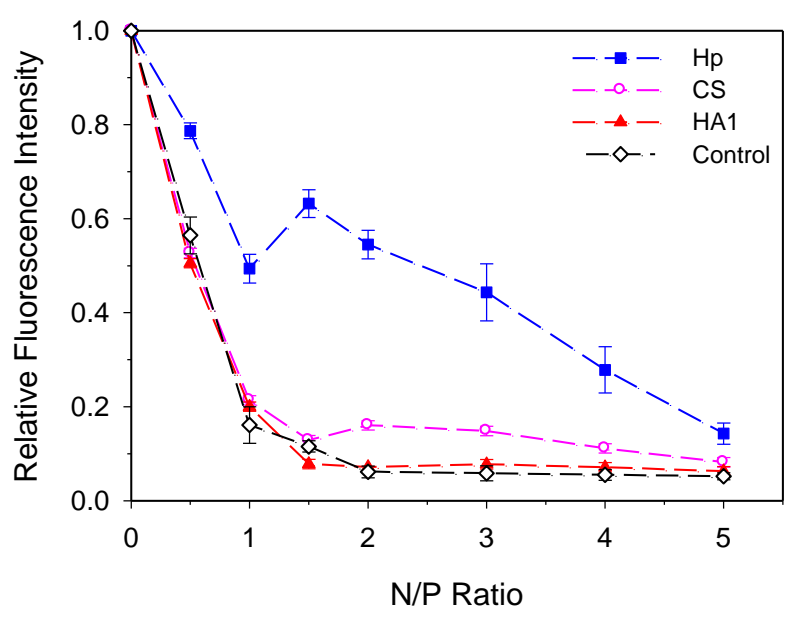


Figure 2. Fluorescence intensity of Picogreen bound to DNA released from DNA/chitosan (80\% DDA, $76 \mathrm{kDa}$ ) complexes upon exposure to different competing polyanions (Hp, CS, and HA1). The complexes were exposed to $1.8 \mu \mathrm{g} / \mathrm{mL}$ of competing polyanion, except for the controls.

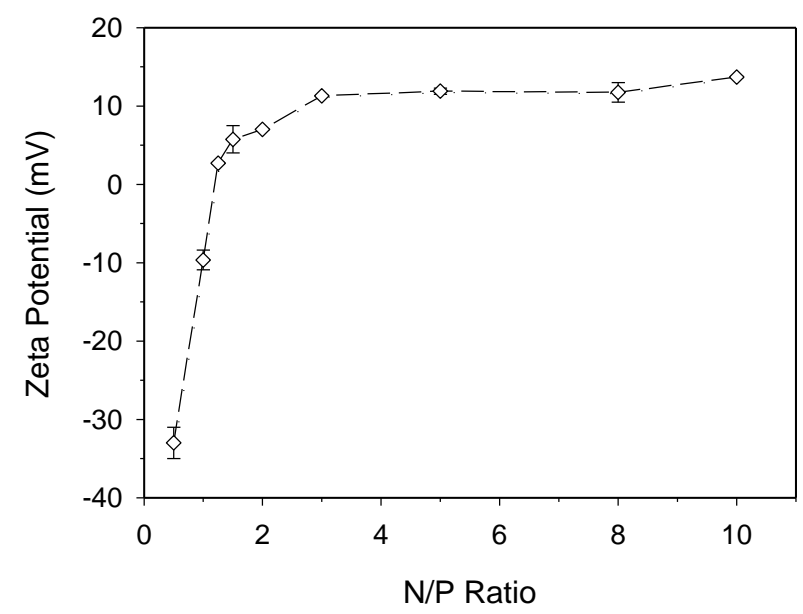

Figure 3. Zeta Potentials of DNA/chitosan $(80 \%$ DDA, $76 \mathrm{kDa})$ complexes prepared at different $\mathrm{N} / \mathrm{P}$ ratios (in $25 \mathrm{mM}$ MES buffer, $\mathrm{pH} 6.5$, total ionic strength of $150 \mathrm{mM}$ adjusted by addition of $\mathrm{NaCl})$.

The initially prepared dispersions of DNA/chitosan $(80 \%$ DDA, $76 \mathrm{kDa})$ complexes were then exposed to $1.8 \mu \mathrm{g} / \mathrm{mL}$ of either $\mathrm{HA} 1, \mathrm{CS}$, or $\mathrm{Hp}$. At this concentration, the amount of negative charge of the competing polyanion was always in excess compared to that of DNA phosphate groups in the samples. These polyanions at the range of concentrations tested in this study did not interfere in the detection and quantification of free DNA by Picogreen, in agreement with a previous report [56]. The relative fluorescence intensities of Picogreen bound to DNA in dispersions of DNA/chitosan complexes with addition of a competing polyanion are also shown in Figure 2. The DNA/chitosan complexes exposed to HA1 resulted in similar fluorescence intensities of the dye as in the controls without any added competing polyanion. Increasing the concentration up to $17 \mu \mathrm{g} / \mathrm{mL}$ of HA1 in the samples also did not result in any significant changes in the measured fluorescence intensities (data not shown). These observations indicate that HA was unable to disrupt the DNA/chitosan binding, in agreement with a previous report using fully deacetylated chitosans to 
form complexes with DNA [32]. The exposure of DNA/chitosan complexes to CS resulted in a slight but not significant increase of the fluorescence intensity of bound Picogreen, compared to the controls in the range of N/P ratios between 2 and 4 (Figure 2). We did not detect further release of DNA from these complexes upon increasing the amount of competing CS (data not shown). Similar results in the presence of HA1 or CS were found when complexes were prepared with a chitosan of $80 \%$ DDA and a $M_{\mathrm{n}}$ of $11 \mathrm{kDa}$ (data not shown). In contrast to the competition with HA and CS, exposure of DNA/chitosan complexes to $1.8 \mu \mathrm{g} / \mathrm{mL}$ of Hp resulted in significant destabilization, as indicated by the increased fluorescence intensities relative to the controls (Figure 2). The destabilization of the complexes was even observed in the dispersion with an N/P ratio of 0.5 where the DNA/chitosan complexes were negatively charged with a zeta potential of $-33( \pm 2) \mathrm{mV}$ (Figure 3). The charge repulsion by a negative zeta potential did not prevent Hp from disrupting the complexes and consequently releasing DNA in solution for binding with the dye. However, not all DNA was released. These observations suggest strong competition between $\mathrm{Hp}$ and DNA for binding to chitosan as well as strong binding affinities of chitosan with both DNA and Hp.

The ability of competing polyanions to destabilize the DNA/chitosan complexes appears related to their negative charge density, or equivalently the number of charge groups per dissaccharide, as suggested in previous studies on polymeric and liposomal based gene delivery systems $[32,33,66$, 67]. HA did not destabilize the DNA/chitosan complexes most probably due to its low negative charge density with only one carboxyl group per disaccharide unit. The additional sulfate group on the disaccharide unit of CS compared to HA had a slight effect on DNA release while only heparin with 2 sulfate and 1 carboxyl group per disaccharide was able to significantly compete with DNA for binding to chitosan resulting in the disruption of the complexes.

Binding Affinity Between Chitosan and Different Polyanions. The competition binding assay using Picogreen to detect released DNA from chitosan binding in the complexes does not provide a direct measurement of the binding affinity between oppositely charged polyelectrolytes, but rather information about the stability of the complexes against competition with polyanions. We did 
however determine binding constants using isothermal titration microcalorimetry (ITC) for chitosan interacting with different polyanions, including DNA, Hp, CS, and HA2. We used a chitosan with a DDA of $80 \%$ and a $M_{\mathrm{n}}$ of $11 \mathrm{kDa}$ for ITC measurements. The isotherms are presented in Figure 4 showing the heats of binding normalized to the amount of chitosan titrated into each solution of polyanion, all in $25 \mathrm{mM}$ MES buffer at $\mathrm{pH} 6.5$ with a total ionic strength of $150 \mathrm{mM}$, and presented as a function of the number of glucosamine units in chitosan to the number of negative charges in the polyanion. The interactions of chitosan-DNA, chitosan-Hp, and chitosan-CS were exothermic in the MES buffer that was also used in the competition binding assay. The titrations of chitosan into the solution of HA2 yielded negligible heat changes compared to the other studied binary systems. 


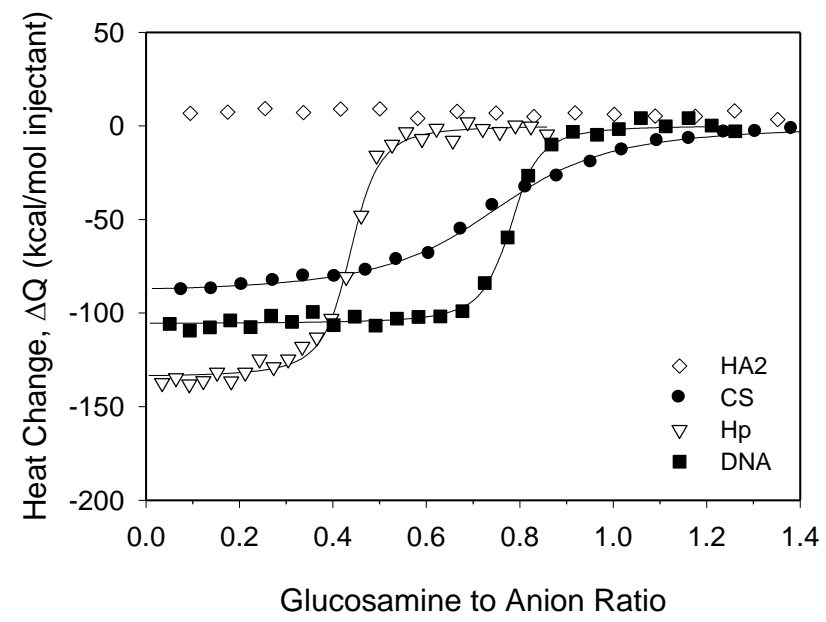

Figure 4. Heats of interaction from calorimetric titrations of chitosan $(80 \% \mathrm{DDA}, 11 \mathrm{kDa})$ into different types of polyanions: HA2, CS, Hp, and DNA (in $25 \mathrm{mM}$ MES buffer, $\mathrm{pH}$ 6.5, and total ionic strength of $150 \mathrm{mM}$ adjusted by addition of $\mathrm{NaCl}$ ). Solid lines represent best-fits generated from the SSIS model.

The enthalpy of binding, $\Delta H_{\mathrm{obs}}$, the binding stoichiometry, $n$, and the binding constant, $K_{\mathrm{obs}}$, determined from fitting the SSIS model to the ITC isotherms of the different systems are summarized in Table 2. The degree of ionization of chitosan in the unbound state was $46 \%$ in the MES buffer at $\mathrm{pH} 6.5$ with a total ionic strength of $150 \mathrm{mM}$, calculated as previously described [28, 68]. However, we have demonstrated in a previous study that DNA induces proton transfer from the buffer to chitosan, as revealed by the dependence of the measured heat release on the nature of the buffer [28]. The observed enthalpy of binding ( $\left.\Delta H_{\mathrm{obs}}\right)$ was found in that study to be almost entirely accounted for by the heats associated with proton transfer. Therefore, the values of $\Delta H_{\text {obs }}$ determined here for the interactions of chitosan-DNA, chitosan-Hp, and chitosan-CS are not necessarily the intrinsic enthalpy of binding because they can contain contributions from the ionization changes of the buffer and of chitosan. The ionization state of chitosan can be increased to a greater extent in the complexed form because of proton transfer. The use of buffers with different enthalpy of ionization is required for the determination of the number of transferred protons [28, 69] which was not within the scope of this study. In contrast to $\Delta H_{\mathrm{obs}}$, the binding constant and the stoichiometry of binding are parameters found to be independent of buffer choice $[28,70]$. The binding constant between 
chitosan and DNA was $3.8 \times 10^{8} \mathrm{M}^{-1}$ determined from fitting the corresponding isotherm in Figure 4. This value is about 40 -fold higher than the binding constant obtained for chitosan-CS, which explains the observed inability of CS to disrupt the DNA/chitosan complexes. On the other hand, heparin was able to disrupt the DNA/chitosan complexes and release DNA into solution because the binding affinities of chitosan-Hp and chitosan-DNA are similar; the latter value being only 2-fold higher. This finding suggests that any extracellular and intracellular components with similar or higher binding affinities for chitosan could disrupt the DNA/chitosan complexes. Such components can include cellular RNA which is structurally similar to DNA and present in the cytoplasm at high concentrations. RNA was found to induce DNA dissociation from PEI [41] and polyamine gene vectors [30] and was suggested to be involved in the intracellular disassembly of these complexes prior to enter the nucleus for gene expression.

The negligible heat changes detected during titrations of chitosan into a solution of HA2 (Figure 4) suggest that this low charge density polyanion, compared to DNA and Hp, did not bind to chitosan to induce proton transfer from the buffer to chitosan under conditions of $\mathrm{pH} 6.5$ and total ionic strength of $150 \mathrm{mM}$. Since binding is electrostatically driven, we increased it by decreasing the ionic strength to $18 \mathrm{mM}$ and carrying out ITC measurements. The heat changes at $18 \mathrm{mM}$ ionic strength were significantly higher (Figure 5), than at an ionic strength of $150 \mathrm{mM}$ which screened electrostatic attraction between the oppositely charged polyelectrolytes. In both ionic strengths, we cannot exclude possible interactions between chitosan and HA, that are athermal and thereby not detectable by ITC, since negligible heat changes have been previously reported for fully ionized oppositely charged polyelectrolytes undergoing complexation [28, 45]. The binding constant of chitosan-HA2 determined at $18 \mathrm{mM}$ of ionic strength was $1 \times 10^{-7} \mathrm{M}$. This value is still about 200 fold lower than the binding constant of chitosan-DNA under similar conditions of $\mathrm{pH}$ and ionic strength (Figure 5 and Table 2) indicating a weak ability of HA to compete with DNA for chitosan binding, in agreement with results obtained from the competition binding assay using Picogreen. 
Table 2. Parameters of Interaction from fitting of the SSIS Model to Isotherms of Chitosan ( $80 \%$ DDA, $11 \mathrm{kDa}$ ) with different Polyanions in $25 \mathrm{mM}$ MES Buffer at $\mathrm{pH} 6.5$ with different ionic strengths.

\begin{tabular}{lcccc}
\hline Polyanion & $n^{a}$ & $n_{\mathrm{N}: \text { Anion }}{ }^{b}$ & $\begin{array}{c}\Delta \boldsymbol{H}_{\mathbf{o b s}} \\
(\mathrm{kcal} / \mathrm{mol})\end{array}$ & $\begin{array}{c}\boldsymbol{K}_{\text {obs }} \\
\left(\mathbf{x} \mathbf{1 0}^{7} \mathrm{M}^{-1}\right)\end{array}$ \\
\hline
\end{tabular}

$\begin{array}{lcccc}\text { A) Total Ionic Strength }=\mathbf{1 5 0} \mathbf{~ m M} \\ \text { DNA } & 180 \pm 9 & 0.72 \pm 0.03 & -107 \pm 1 & 38 \pm 1 \\ \text { Hp } & 1.4 \pm 0.0 & 0.42 \pm 0.01 & -156 \pm 22 & 19 \pm 5 \\ \text { CS } & 1.4 \pm 0.0 & 0.74 \pm 0.01 & -87 \pm 2 & 1 \pm 0\end{array}$

HA2

B) Total Ionic Strength $=18 \mathrm{mM}$

$\begin{array}{lcccc}\text { DNA } & 199 \pm 11 & 0.80 \pm 0.04 & -194 \pm 2 & 206 \pm 93 \\ \text { HA2 } & 1.0 \pm 0.0 & 0.98 \pm 0.00 & -91 \pm 0 & 1 \pm 0\end{array}$

${ }^{a}$ The number of moles of binding sites for chitosan on each mole of polyanion. ${ }^{b}$ The ratio of glucosamine to anion groups in the complex when all binding sites are occupied at saturation (calculated from $n$ ). The parameters $n, \Delta H_{\mathrm{obs}}$ and $K_{\mathrm{obs}}$ were determined from the SSIS model fit using the molar concentration of chitosan and polyanion as the binding entities and not their glucosamine and anions groups. Means are shown with error representing minimum and maximum of duplicates.

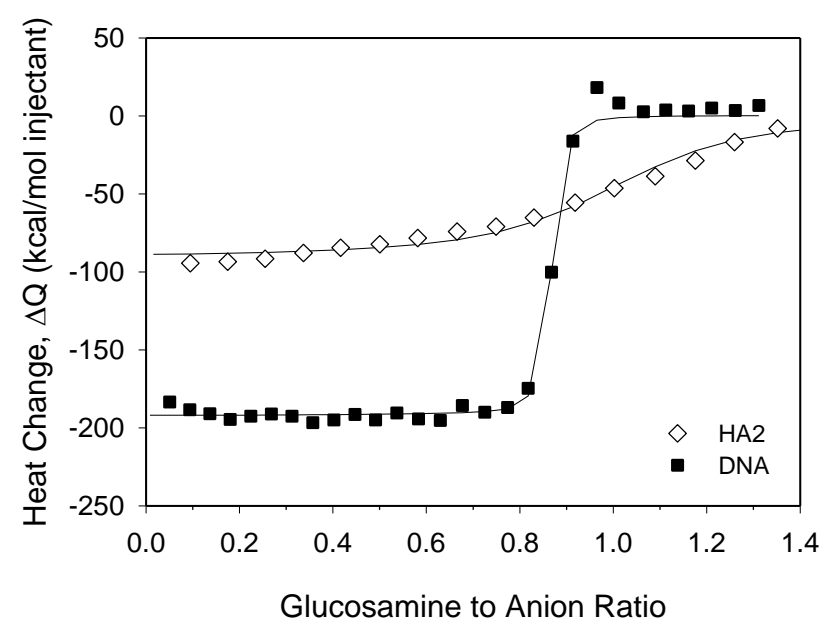

Figure 5. Heats of interaction from calorimetric titrations of chitosan ( $80 \%$ DDA, $11 \mathrm{kDa})$ into HA2 and DNA (in $25 \mathrm{mM}$ MES buffer, $\mathrm{pH}$ 6.5, without $\mathrm{NaCl}$ ). Solid lines represent best-fits generated from the SSIS model. 


\section{Effect of the Chitosan Degree of Deacetylation and Molecular Weight on the Stability of the}

Complexes. The charge density of chitosan can be modulated by its degree of deacetylation (DDA), defined as the fractional content of glucosamine monomers. Increasing the DDA of chitosan increases the charge density along the molecular chain of chitosan, which was previously found to enhance the binding affinity for DNA by ITC [28] and ethidium bromide displacement assay [46]. The effect of DDA on the stability of DNA/chitosan complexes upon exposure to heparin was assessed using Picogreen for detection of DNA release. Dispersions of DNA/chitosan complexes were prepared at different $\mathrm{N} / \mathrm{P}$ ratios using chitosans having a similar $M_{\mathrm{n}}$ of $\sim 80 \mathrm{kDa}$ but different DDA values ranging from $72 \%$ to $98 \%$. These complexes were then exposed to increasing concentrations of $\mathrm{Hp}$ from 0 to $8.4 \mu \mathrm{g} / \mathrm{mL}$. The fluorescence intensities of these samples measured after addition of Picogreen are shown in Figure 6 A, B, and C. The exposure of the complexes to 1.8 $\mu \mathrm{g} / \mathrm{mL}$ of Hp clearly destabilized the complexes and released DNA to an extent dependent on DDA and $\mathrm{N} / \mathrm{P}$ ratio. Increasing the chitosan DDA from $72 \%$ to $80 \%$ did not significantly improve the stability of the complexes against disruption by $\mathrm{Hp}$ at this concentration since similar amounts of DNA released from the complexes were bound to Picogreen. However, the chitosan of 98\% DDA clearly renders the complexes more stable and less vulnerable to the dissociation by heparin. The ability to resist dissociation by $\mathrm{Hp}$ is an indication of stronger binding between DNA and chitosan of $98 \%$ DDA. These observations are in agreement with our previous study in which the binding constant determined for chitosan-DNA did not change significantly as the DDA increased from $72 \%$ to $80 \%$ but increased almost 3 -fold with a DDA of $98 \%$ [28].

Heparin also destabilized the DNA complexes prepared with chitosans having a constant DDA of $80 \%$ but different $M_{\mathrm{n}}$ values, as shown in Figure 7 A, B, and C. However, the ability of these complexes to resist dissociation by heparin was enhanced with increasing chitosan molecular weight from 11 to $153 \mathrm{kDa}$. Similar findings were previously reported using also heparin to disrupt DNA complexes prepared with fully deacetylated chitosans of different molecular weights [32]. This increased stability is attributed to the higher affinity of DNA for binding to longer chitosans as previously demonstrated by ITC [28]. 

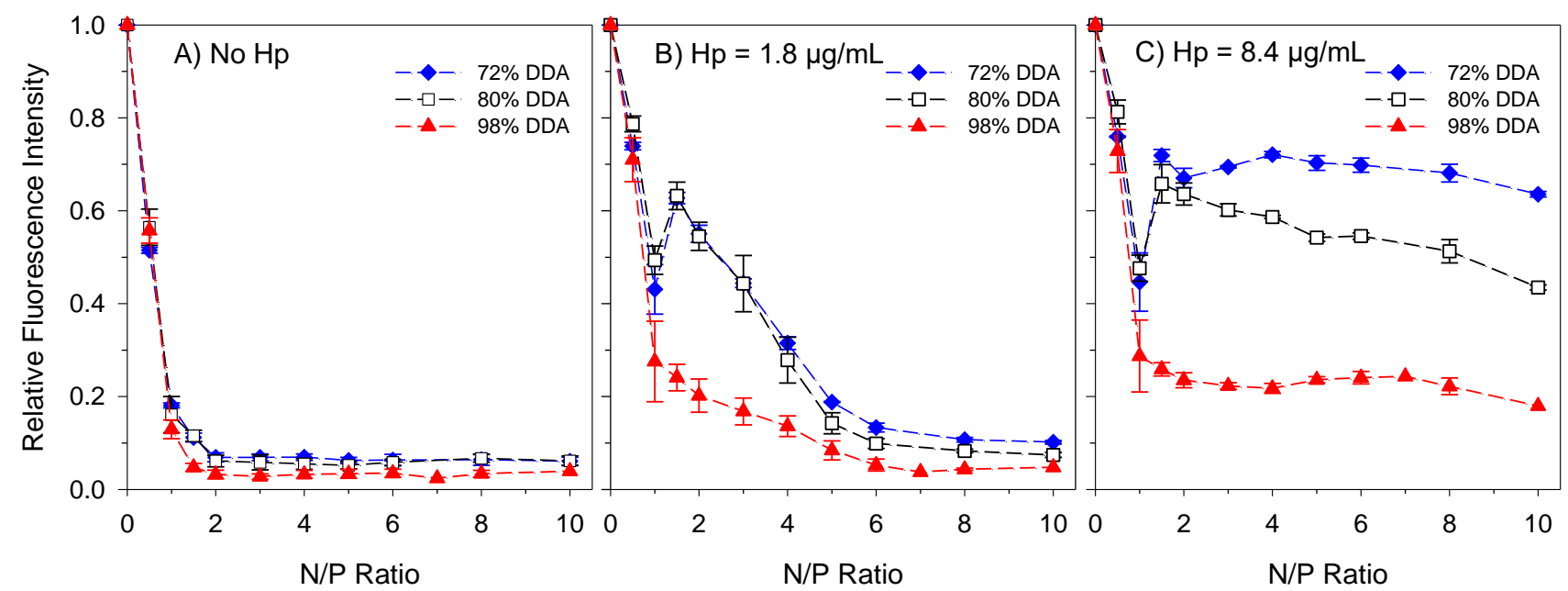

Figure 6. Fluorescence intensity of Picogreen bound to DNA released from DNA/chitosan complexes upon exposure to heparin. The complexes were prepared with chitosans of different DDA $\left(M_{\mathrm{n}} \sim 80 \mathrm{kDa}\right)$ and then exposed to (A) no $\mathrm{Hp}$, (B) $1.8 \mu \mathrm{g} / \mathrm{mL}$ of Hp, and (C) $8.4 \mu \mathrm{g} / \mathrm{mL}$ of Hp.

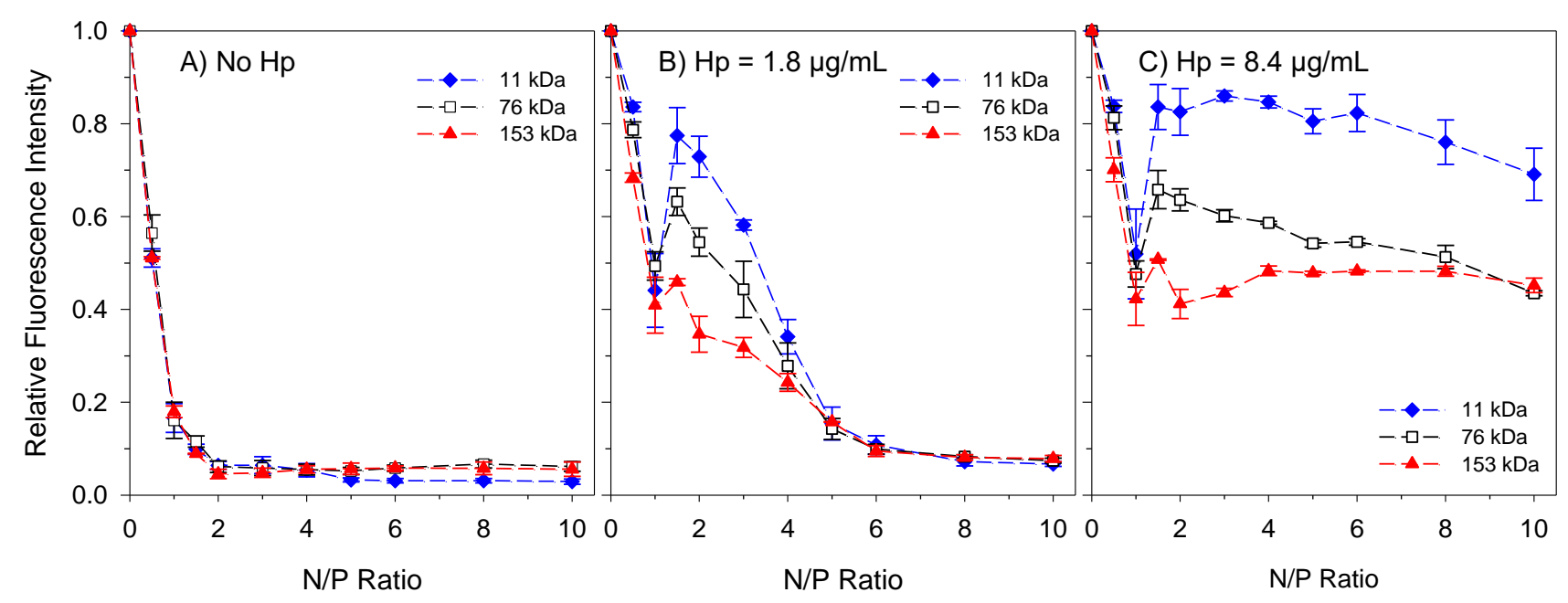

Figure 7. Fluorescence intensity of Picogreen bound to DNA released from DNA/chitosan complexes upon exposure to heparin. The complexes were prepared with chitosans of different $M_{\mathrm{n}}$ $(\mathrm{DDA}=80 \%$ ) and then exposed to (A) no $\mathrm{Hp},(\mathrm{B}) 1.8 \mu \mathrm{g} / \mathrm{mL}$ of $\mathrm{Hp}$, and (C) $8.4 \mu \mathrm{g} / \mathrm{mL}$ of $\mathrm{Hp}$.

Strong bindings of DNA with chitosans of high DDA or molecular weights are desirable to resist nuclease degradation and premature dissociation by competing polyanions but yields, on the other hand, complexes that are too stable to transfect cells since they cannot disassemble inside the cells 
for gene expression. The level of gene expression was previously found to decrease substantially when the chitosan DDA increased from $80 \%$ to $98 \%$ with similar $M_{\mathrm{n}}$ of about $80 \mathrm{kDa}$ [25] However, the decrease of the DDA from $90 \%$ to $70 \%$ and $62 \%$ of a chitosan of $390 \mathrm{kDa}$ resulted also in reduced gene expression levels, which were attributed to the observed destabilization of DNA/chitosan complexes by serum proteins when the DDA was lower than $90 \%$ [71]. Chitosans with DDA values $>90 \%$ combined with high molecular weights ( $>100 \mathrm{kDa})$ [24-26] showed poor transfection efficacy. These formulations that were found to be highly stable against disruption by heparin $[26,32]$ resulted also in slow increases of gene expression with time, suggesting slow and inefficient release of DNA from the complexes once inside the cells [26]. On the other hand, complexes formed with chitosans of too low molecular weights $(<5 \mathrm{kDa})$ were found to dissociate prematurely in transfection medium as determined by gel electrophoresis and resulted in both low cellular uptake and low efficacy of transfection [26]. The release of DNA found in our study, which was induced by addition of heparin, is consistent with these previous findings relating transfection efficiency to DDA and $M_{\mathrm{n}}$ via stability arguments. A balance between complex stability and protection of DNA but retaining the ability to dissociate inside the cell must be achieved for efficient gene delivery, as previously found via observation of the coupling of either low $M_{\mathrm{n}}$ with high DDA or high $M_{\mathrm{n}}$ with low DDA values of chitosans [25]. Results published by other groups suggesting that this balance of stability could also be achieved by modification of polycations, such as chitosan [26] and PEI,[20] with uncharged groups to lower the binding affinity to DNA.

\section{Role of Free Chitosan in Dispersions of DNA/Chitosan Complexes Exposed to Competing}

Polyanions. The amount of DNA released upon disruption of the DNA/chitosan complexes by heparin was dependent on the N/P ratio used to prepare the dispersions (Figure 6 B and C; Figure 7 B and C). The drop of the fluorescence intensity observed for formulations prepared at an N/P ratio of 1 , and followed by a sudden increase in intensity at an N/P ratio of 1.5 , was probably due to precipitation of most DNA/chitosan complexes formed near the point of charge neutralization prior to addition of $\mathrm{Hp}$. Near the point of neutralization $(\mathrm{N} / \mathrm{P} \approx 1)$, lower amounts of chitosan and DNA 
were consequently available in solution for the competition binding with $\mathrm{Hp}$, in comparison to the dispersions with an excess of DNA $(\mathrm{N} / \mathrm{P}<1)$ or chitosan $(\mathrm{N} / \mathrm{P}>1)$ that generate sufficiently charged complexes to prevent precipitation (Figure 3). For the dispersions exposed to $1.8 \mu \mathrm{g} / \mathrm{mL}$ of $\mathrm{Hp}$ (Figure 6 B; Figure 7 B), the fluorescence intensity reached its highest value at N/P $=1.5$ and decreased with higher chitosan content until reaching values comparable with those measured for the samples without addition of heparin at $\mathrm{N} / \mathrm{P}$ ratios above 6. Dispersions of DNA/polycation complexes prepared under similar conditions were found to contain a significant amount of free polycation in solution [13-16]. Free chitosan was eventually detected in our dispersions with N/P ratios at above 5 from analysis by polyacrylamide gel electrophoresis coupled with Coomassie blue staining (Figure 8). This finding together with the negligible amounts of DNA released from the complexes at N/P ratios above 6 suggests that sufficient amounts of chitosan were available for binding to both DNA and heparin $(1.8 \mu \mathrm{g} / \mathrm{mL})$, and prevent disruption of the complexes. In the presence of a higher concentration of $\mathrm{Hp}(8.4 \mu \mathrm{g} / \mathrm{mL})$, much larger amounts of chitosan in the dispersions were required to prevent dissociation of the DNA/chitosan complexes (Figure 6 C; Figure $7 \mathrm{C}$ ) beyond the amount present with $\mathrm{N} / \mathrm{P}=10$, the highest value measured here. These results indicate that heparin first binds to free chitosan and then to disrupt the complexes by binding to chitosan in the complexes once the free fraction has been saturated.

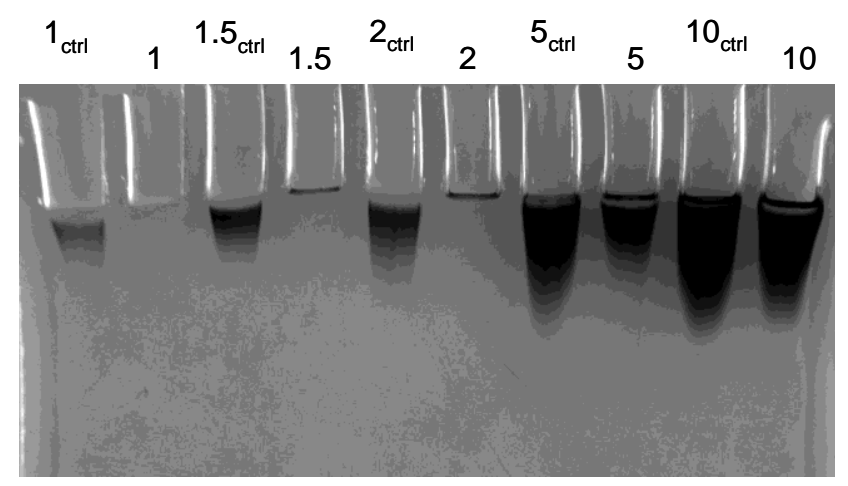

Figure 8. Polyacrylamide gel electrophoresis of DNA/chitosan $(80 \%$ DDA, $76 \mathrm{kDa})$ complexes prepared at N/P ratios from 1 to 10 , showing the bands of free chitosan stained with Coomassie brilliant blue. The controls (ctrl) correspond to solutions of chitosan at the same concentrations as in the dispersions but without DNA. 
To further explore the role of free chitosan content in dispersions of DNA/chitosan complexes, we quantified free chitosan content by subjecting the samples to the depletion method with the Orange II dye. The free chitosan contents presented in Figure 9 A were determined for dispersions of DNA/chitosan $(80 \%$ DDA, $76 \mathrm{kDa})$ complexes after dilution with either deionized water or MES buffer at pH 6.5 (total ionic strength of $150 \mathrm{mM}$ ). The dilution of the dispersions with water enabled the quantification of free chitosan under conditions that do not alter the physical properties of the DNA/chitosan complexes initially formed in a solution $\mathrm{pH}$ of 4.0-5.5. Under such conditions, the free chitosan content increased from $40 \%$ to $85 \%$ as the $\mathrm{N} / \mathrm{P}$ ratio increased from 2 to 10 in the dispersions. These free chitosan contents are consistent with those previously determined by asymmetrical flow field-flow fractionation (AF4) $[12,13]$. Compared to the dispersions diluted with water, the dilution of the same dispersions but with the MES buffer yielded lower fractions of free chitosan ranging from $26 \%$ to $76 \%$ as the N/P ratio increased from 2 to 10 , indicating further incorporation of chitosan into the initially formed complexes due to partial neutralization of chitosan at the higher $\mathrm{pH}$ of 6.5 . Based on free chitosan content, we calculated the N/P ratio of the complexes themselves using and found ranges of N/P of 1.3-1.5 in the dispersions diluted with water and 2.02.5 in MES buffer at $\mathrm{pH}$ 6.5. These values were essentially independent of the N/P ratio used to prepare the dispersions in the range of 3 to 10 (Figure $9 \mathrm{~B}$ ). Therefore, the dispersions with an N/P ratio of 6 contained about $60 \%$ of free chitosan in the MES buffer (Figure 9 A). This fraction of free chitosan protected against the disruption of the DNA/chitosan complexes by heparin (Figure 6 B; Figure $7 \mathrm{~B}$ ) since the amount of free chitosan was sufficient to accommodate the binding of 1.8 $\mu \mathrm{g} / \mathrm{mL}$ of $\mathrm{Hp}$ (corresponding to an amount of negative charges that was 3-fold higher than the DNA charges in the samples). However, the free chitosan content was not sufficient when the dispersions were exposed to $8.3 \mu \mathrm{g} / \mathrm{mL}$ of $\mathrm{Hp}$ (Figure $6 \mathrm{C}$; Figure $7 \mathrm{C}$ ). To prevent the dissociation of the complexes by $\mathrm{Hp}$ at this concentration, the $\mathrm{N} / \mathrm{P}$ ratio in the formulations must be increased substantially to increase the concentration of free polycation in the dispersions, beyond the maximal N/P of 10 used in this study. Although using higher concentration of free polycation would stabilize 
complexes against a large excess of competing polyanions, it was found that there is an optimal N/P ratio value beyond which cellular uptake of the complexes and gene expression levels decrease [16, 26]. We demonstrated here that the free polycation may beneficially prevent premature dissociation of the complexes by competing polyanions but, on the other hand, it may reduce biological effectiveness if in great excess $[16,26]$.
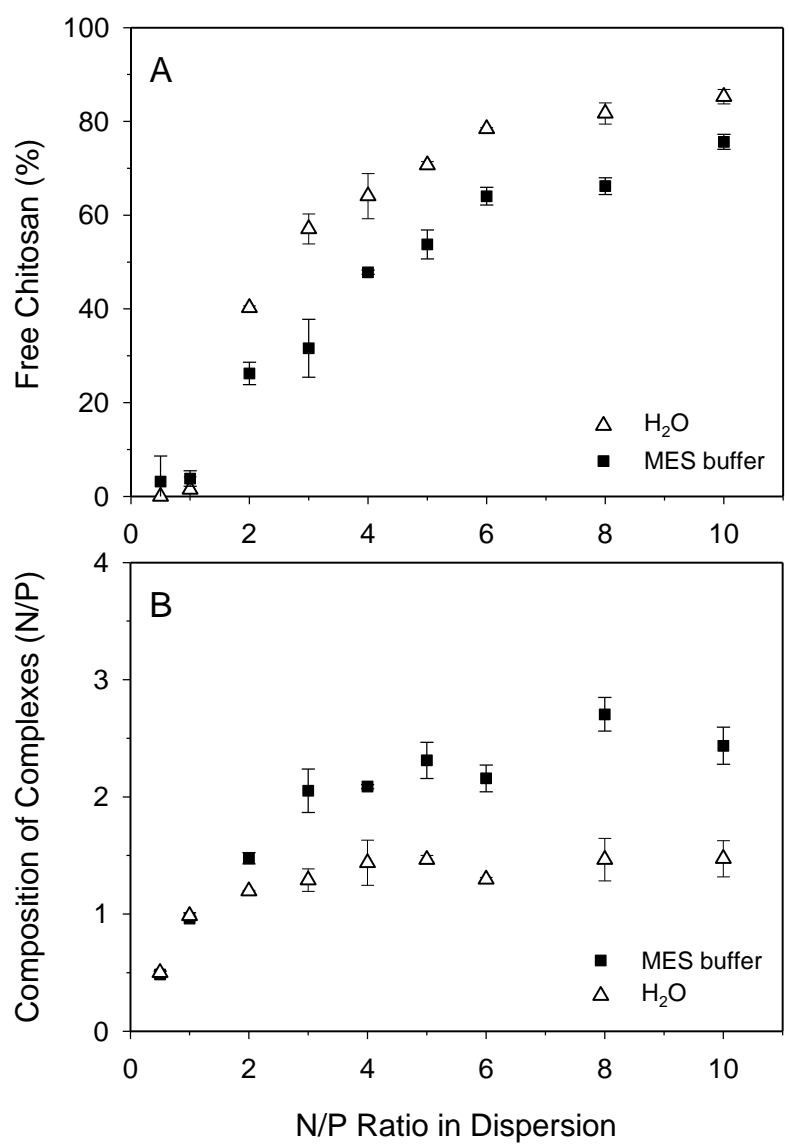

Figure 9. Free chitosan content (A) and composition of complexes in terms of N/P ratio (B) in dispersions of DNA/chitosan $(80 \% \mathrm{DDA}, 76 \mathrm{kDa})$ complexes initially prepared at different $\mathrm{N} / \mathrm{P}$ ratios and further diluted with deionized water or $25 \mathrm{mM}$ MES buffer at $\mathrm{pH} 6.5$ (total ionic strength of $150 \mathrm{mM}$ ). The fractions of free chitosan were determined by subjecting the samples to ultracentrifugation and the collected supernatants were analyzed by the Orange II depletion method.

\section{Conclusions}

We have examined the ability of biological polyanions to disrupt DNA/chitosan complexes and related this to their binding affinity to chitosan. The inability of hyaluronic acid and chondroitin sulfate to destabilize DNA/chitosan complexes is attributed to their substantially lower binding 
constants with chitosan compared to the chitosan-DNA binding constant as determined by ITC. Among the competing polyanions investigated here, only heparin with the highest charge density has a binding affinity with chitosan that is comparable to that of DNA. Heparin was able to displace DNA to an extent that was dependent on the concentration of heparin and on the N/P ratio in the dispersions. The higher stability of DNA/chitosan complexes with higher N/P ratios when exposed to heparin was due to the presence of free chitosan binding to added heparin. We found that heparin first binds to free chitosan without disrupting the DNA/chitosan complexes and once the free chitosan component is saturated with heparin, further addition releases DNA from the complexes through competitive binding to chitosan. This finding suggests that free polycation can prevent premature dissociation of the complexes upon interactions with anionic biological components in physiological media. Literature suggests that this free polycation fraction is required to induce endosomal escape through the proton sponge effect and ensure transfection efficiency of the complexes while excessive amounts can impede cellular uptake and induce cytotoxicity depending on polycation type. The stability of the complexes also depends on the chitosan DDA and molecular weight, in agreement with the transfection efficiency and binding affinity dependence on these parameters where increasing DDA or molecular weight increases binding affinity to DNA and thereby complex stability. Increasing chitosan DDA or molecular weight resulted in more stable complexes while decreasing these parameters led to unstable complexes in the presence of heparin. These findings provide guidelines for the design of effective gene delivery systems where the balance between the polycation-DNA binding strength and the intracellular ability to dissociate complexes and release DNA for gene expression is required.

Acknowledgment. The authors thank Nicolas Tran-Khanh for proof-reading the manuscript. This work was supported by the Canadian Institutes of Health Research (CIHR) and by the Natural Sciences and Engineering Research Council of Canada (NSERC). Pei Lian Ma received a doctoral fellowship from the Fonds québécois de la recherche sur la nature et les technologies (FQRNT). 


\section{References}

1. Behr, J.-P., The Proton Sponge: a Trick to Enter Cells the Viruses Did Not Exploit. Chimia, 1997. 51: p. 34-36.

2. Boussif, O., et al., A versatile vector for gene and oligonucleotide transfer into cells in culture and in vivo: polyethylenimine. Proc. Natl. Acad. Sci. USA, 1995. 92(16): p. 72977301.

3. Yang, S. and S. May, Release of cationic polymer-DNA complexes from the endosome: A theoretical investigation of the proton sponge hypothesis. J. Chem. Phys., 2008. 129(18): p. 185105-9.

4. Akinc, A., et al., Exploring polyethylenimine-mediated DNA transfection and the proton sponge hypothesis. Journal of Gene Medicine, 2005. 7(5): p. 657-663.

5. Sonawane, N.D., F.C. Szoka, Jr., and A.S. Verkman, Chloride accumulation and swelling in endosomes enhances DNA transfer by polyamine-DNA polyplexes. J Biol Chem, 2003. 278(45): p. 44826-31.

6. Freeman, E.C., L.M. Weiland, and W.S. Meng, Modeling the proton sponge hypothesis: examining proton sponge effectiveness for enhancing intracellular gene delivery through multiscale modeling. Journal of Biomaterials Science-Polymer Edition, 2013. 24(4): p. 398416.

7. Richard, I., et al., Ionization Behavior of Chitosan and Chitosan-DNA Polyplexes Indicate That Chitosan Has a Similar Capability to Induce a Proton-Sponge Effect as PEI. Biomacromolecules, 2013. 14(Copyright (C) 2014 American Chemical Society (ACS). All Rights Reserved.): p. 1732-1740.

8. Benjaminsen, R.V., et al., The Possible "Proton Sponge" Effect of Polyethylenimine (PEI) Does Not Include Change in Lysosomal pH. Molecular Therapy, 2013. 21(1): p. 149-157.

9. Bieber, T., et al., Intracellular route and transcriptional competence of polyethylenimineDNA complexes. Journal of Controlled Release, 2002. 82(2-3): p. 441-454. 
10. Leroueil, P.R., et al., Wide varieties of cationic nanoparticles induce defects in supported lipid bilayers. Nano Letters, 2008. 8(2): p. 420-424.

11. Parhamifar, L., et al., Polycation cytotoxicity: a delicate matter for nucleic acid therapyfocus on polyethylenimine. Soft Matter, 2010. 6(17): p. 4001-4009.

12. Ma, P.L., M.D. Buschmann, and F.M. Winnik, Complete physicochemical characterization of DNA/chitosan complexes by multiple detection using asymmetrical flow field-flow fractionation. Anal Chem, 2010. 82(23): p. 9636-43.

13. Ma, P.L., M.D. Buschmann, and F.M. Winnik, One-Step Analysis of DNA/Chitosan Complexes by Field-Flow Fractionation Reveals Particle Size and Free Chitosan Content. Biomacromolecules, 2010. 11(3): p. 549-554.

14. Clamme, J.P., J. Azoulay, and Y. Mely, Monitoring of the Formation and Dissociation of Polyethylenimine/DNA Complexes by Two Photon Fluorescence Correlation Spectroscopy. Biophys. J., 2003. 84(3): p. 1960-1968.

15. Reitan, N.K., et al., Characterizing DNA Condensation by Structurally Different Chitosans of Variable Gene Transfer Efficacy. Biomacromolecules, 2009. 10(6): p. 1508-1515.

16. Boeckle, S., et al., Purification of polyethylenimine polyplexes highlights the role of free polycations in gene transfer. J. Gene Med., 2004. 6(10): p. 1102-1111.

17. Niebel, Y., et al., Combined Analysis of Polycation/ODN Polyplexes by Analytical Ultracentrifugation and Dynamic Light Scattering Reveals their Size, Refractive Index Increment, Stoichiometry, Porosity, and Molecular Weight. Biomacromolecules, 2014. 15(3): p. $940-947$.

18. Thibault, M., et al., Excess polycation mediates efficient chitosan-based gene transfer by promoting lysosomal release of the polyplexes. Biomaterials, 2011. 32(20): p. 4639-4646.

19. Schaffer, D.V., et al., Vector unpacking as a potential barrier for receptor-mediated polyplex gene delivery. Biotechnol. Bioeng., 2000. 67(5): p. 598-606. 
20. Gabrielson, N.P. and D.W. Pack, Acetylation of Polyethylenimine Enhances Gene Delivery via Weakened Polymer/DNA Interactions. Biomacromolecules, 2006. 7(8): p. 2427-2435.

21. Itaka, K., et al., In situ single cell observation by fluorescence resonance energy transfer reveals fast intra-cytoplasmic delivery and easy release of plasmid DNA complexed with linear polyethylenimine. J. Gene Med., 2004. 6(1): p. 76-84.

22. Ito, T., et al., Hyaluronic acid and its derivative as a multi-functional gene expression enhancer: Protection from non-specific interactions, adhesion to targeted cells, and transcriptional activation. J. Control. Release, 2006. 112(3): p. 382-388.

23. Koyama, Y., et al., Enhancement of Transcriptional Activity of DNA Complexes by Amphoteric PEG Derivative. Biomacromolecules, 2006. 7(4): p. 1274-1279.

24. Sato, T., T. Ishii, and Y. Okahata, In vitro gene delivery mediated by chitosan. Effect of pH, serum, and molecular mass of chitosan on the transfection efficiency. Biomaterials, 2001. 22(15): p. 2075-2080.

25. Lavertu, M., et al., High efficiency gene transfer using chitosan/DNA nanoparticles with specific combinations of molecular weight and degree of deacetylation. Biomaterials, 2006. 27(27): p. 4815-4824.

26. Strand, S.P., et al., Molecular design of chitosan gene delivery systems with an optimized balance between polyplex stability and polyplex unpacking. Biomaterials, 2010. 31(5): p. 975-987.

27. Thibault, M., et al., Intracellular Trafficking and Decondensation Kinetics of ChitosanpDNA Polyplexes. Molecular Therapy, 2010. 18(10): p. 1787-1795.

28. Ma, P.L., et al., New Insights into Chitosan-DNA Interactions Using Isothermal Titration Microcalorimetry. Biomacromolecules, 2009. 10(6): p. 1490-1499.

29. Thibault, M., et al., Intracellular Trafficking and Decondensation Kinetics of ChitosanpDNA Polyplexes. Molecular Therapy, 2010. In Press. 
30. Huth, S., et al., Interaction of polyamine gene vectors with RNA leads to the dissociation of plasmid DNA-carrier complexes. The Journal of Gene Medicine, 2006. 8(12): p. 1416-1424.

31. Wight, T.N., D.K. Heinegard, and V.C. Hascall, Proteoglycans: Structure and Function, in Cell Biology of Extracellular Matrix, E.D. Hay, Editor. 1991, Plenum Press: New York. p. 45-78.

32. Danielsen, S., et al., Glycosaminoglycan destabilization of DNA-chitosan polyplexes for gene delivery depends on chitosan chain length and GAG properties. Biochim. Biophys. Acta Gen. Subj., 2005. 1721(1-3): p. 44-54.

33. Ruponen, M., et al., Extracellular glycosaminoglycans modify cellular trafficking of lipoplexes and polyplexes. J. Biol. Chem., 2001. 276(36): p. 33875-33880.

34. Duceppe, N. and M. Tabrizian, Factors influencing the transfection efficiency of ultra low molecular weight chitosan/hyaluronic acid nanoparticles. Biomaterials, 2009. 30(13): p. $2625-2631$.

35. Xu, P., G.K. Quick, and Y. Yeo, Gene delivery through the use of a hyaluronate-associated intracellularly degradable crosslinked polyethyleneimine. Biomaterials, 2009. 30(29): p. 5834-5843.

36. Lu, H.D., et al., Novel hyaluronic acid-chitosan nanoparticles as non-viral gene delivery vectors targeting osteoarthritis. Int. J. Pharm., 2011. 420(2): p. 358-365.

37. Chen, C.J., et al., A comparative study of three ternary complexes prepared in different mixing orders of siRNA/redox-responsive hyperbranched poly (amido amine)/hyaluronic acid. Int.J. Nanomedicine, 2012. 7: p. 3837-3849.

38. Hagiwara, K., et al., The effects of coating pDNA/chitosan complexes with chondroitin sulfate on physicochemical characteristics and cell transfection. Biomaterials, 2012. 33(29): p. 7251-7260.

39. Ito, T., et al., DNA/polyethyleneimine/hyaluronic acid small complex particles and tumor suppression in mice. Biomaterials, 2010. 31(10): p. 2912-2918. 
40. Hagiwara, K., et al., In vivo gene transfer using pDNA/chitosan/chondroitin sulfate ternary complexes: influence of chondroitin sulfate on the stability of freeze-dried complexes and transgene expression in vivo. J. Gene Med., 2013. 15(Copyright (C) 2014 American Chemical Society (ACS). All Rights Reserved.): p. 83-92.

41. Bertschinger, M., et al., Disassembly of polyethylenimine-DNA particles in vitro: Implications for polyethylenimine-mediated DNA delivery. J. Control. Release, 2006. 116(1): p. 96-104.

42. Layman, J.M., et al., Influence of Polycation Molecular Weight on Poly(2dimethylaminoethyl methacrylate)-Mediated DNA Delivery In Vitro. Biomacromolecules, 2009. 10(5): p. 1244-1252.

43. Izumrudov, V.A., M.V. Zhiryakova, and A.A. Goulko, Ethidium Bromide as a Promising Probe for Studying DNA Interaction with Cationic Amphiphiles and Stability of the Resulting Complexes. Langmuir, 2002. 18(26): p. 10348-10356.

44. Zelikin, A.N., et al., Competitive reactions in solutions of poly-L-histidine, calf thymus DNA, and synthetic polyanions: Determining the binding constants of polyelectrolytes. J. Am. Chem. Soc., 2003. 125(45): p. 13693-13699.

45. Rungsardthong, U., et al., Effect of Polymer Ionization on the Interaction with DNA in Nonviral Gene Delivery Systems. Biomacromolecules, 2003. 4(3): p. 683-690.

46. Strand, S.P., et al., Influence of Chitosan Structure on the Formation and Stability of DNAChitosan Polyelectrolyte Complexes. Biomacromolecules, 2005. 6(6): p. 3357-3366.

47. Danielsen, S., G. Maurstad, and B.T. Stokke, DNA-polycation complexation and polyplex stability in the presence of competing polyanions. Biopolymers, 2005. 77(2): p. 86-97.

48. Buschmann, M.D., et al., Chitosans for delivery of nucleic acids. Advanced Drug Delivery Reviews, 2013. 65(9): p. 1234-1270.

49. MacLaughlin, F.C., et al., Chitosan and depolymerized chitosan oligomers as condensing carriers for in vivo plasmid delivery. J. Control. Release, 1998. 56(1-3): p. 259-72. 
50. Koping-Hoggard, M., et al., Chitosan as a nonviral gene delivery system. Structure-property relationships and characteristics compared with polyethylenimine in vitro and after lung administration in vivo. Gene Therapy, 2001. 8(14): p. 1108-1121.

51. Nguyen, S., F.M. Winnik, and M.D. Buschmann, Improved reproducibility in the determination of the molecular weight of chitosan by analytical size exclusion chromatography. Carbohydrate Polymers, 2009. 75(3): p. 528-533.

52. Lavertu, M., et al., A validated $1 H$ NMR method for the determination of the degree of deacetylation of chitosan. J. Pharm. Biomed. Anal., 2003. 32(6): p. 1149-1158.

53. Kujawa, P., et al., Construction of Viscoelastic Biocompatible Films via the Layer-by-Layer Assembly of Hyaluronan and Phosphorylcholine-Modified Chitosan. Biomacromolecules, 2007. 8(10): p. 3169-3176.

54. Dragan, A.I., et al., Characterization of PicoGreen interaction with dsDNA and the origin of its fluorescence enhancement upon binding. Biophys J., 2010. 99(9): p. 3010-9.

55. Cosa, G., et al., Photophysical properties of fluorescent DNA-dyes bound to single- and double-stranded DNA in aqueous buffered solution. Photochem. Photobiol., 2001. 73(6): p. 585-99.

56. Singer, V.L., et al., Characterization of PicoGreen reagent and development of a fluorescence-based solution assay for double-stranded DNA quantitation. Anal. Biochem., 1997. 249(2): p. 228-238.

57. Ren, X. and Q.-H. Xu, Label-Free DNA Sequence Detection with Enhanced Sensitivity and Selectivity Using Cationic Conjugated Polymers and PicoGreen. Langmuir, 2008. 25(1): p. 43-47.

58. Moret, I., et al., Stability of PEI-DNA and DOTAP-DNA complexes: effect of alkaline pH, heparin and serum. J. Control. Release, 2001. 76(1-2): p. 169-181.

59. Wiseman, T., et al., Rapid measurement of binding constants and heats of binding using a new titration calorimeter. Anal. Biochem., 1989. 179(1): p. 131-7. 
60. MicroCal LLC., ITC Data Analysis in Origin, Tutorial Guide, Version 7. . 2004, Northampton, MA.

61. Drogoz, A., et al., Polyelectrolyte Complexes from Polysaccharides: Formation and Stoichiometry Monitoring. Langmuir, 2007. 23(22): p. 10950-10958.

62. Hunter, R.J., Foundations of Colloid Science. 2nd edition ed. 2001, Oxford: Oxford University Press. 806.

63. Cleland, R.L., J.L. Wang, and D.M. Detweiler, Polyelectrolyte Properties of Sodium Hyaluronate. 2. Potentiometric Titration of Hyaluronic Acid Macromolecules, 1982. 15: p. 386-395.

64. Bathe, M., et al., A Coarse-Grained Molecular Model for Glycosaminoglycans:Application to Chondroitin, Chondroitin Sulfate, and Hyaluronic Acid. Biophys. J., 2005. 88: p. 38703887.

65. Casu, B. and U. Gennaro, Conductimetric method for the determination of sulfate and carboxyl groups in heparin and other mucopolysaccharides. Carbohydrate Research, 1975. 39(1): p. 168-76.

66. Ruponen, M., S. Yla-Herttuala, and A. Urtti, Interactions of polymeric and liposomal gene delivery systems with extracellular glycosaminoglycans: physicochemical and transfection studies. Biochim. Biophys. Acta Biomembr., 1999. 1415(2): p. 331-341.

67. Ruponen, M., et al., Extracellular and intracellular barriers in non-viral gene delivery. J. Control. Release, 2003. 93(2): p. 213-217.

68. Filion, D., M. Lavertu, and M.D. Buschmann, Ionization and Solubility of Chitosan Solutions Related to Thermosensitive Chitosan/Glycerol-Phosphate Systems. Biomacromolecules, 2007. 8(10): p. 3224-3234.

69. Hinz, H.J., D.D.F. Shiao, and J.M. Sturtevant, Calorimetric investigation of inhibitor binding to rabbit muscle aldolase. Biochemistry, 1971. 10(8): p. 1347-52. 
70. Ehtezazi, T., U. Rungsardthong, and S. Stolnik, Thermodynamic analysis of polycation-DNA interaction applying titration microcalorimetry. Langmuir, 2003. 19(22): p. 9387-9394.

71. Kiang, T., et al., The effect of the degree of chitosan deacetylation on the efficiency of gene transfection. Biomaterials, 2004. 25(22): p. 5293-5301. 